\title{
Energy Inputs, Output and Productivity in Organic and Conventional Maize and Tomato Production, under Mediterranean Conditions
}

\author{
Dimitrios BILALIS 1*, Panoraia-Eirini KAMARIARI², Anestis KARKANIS³, \\ Aspasia EFTHIMIADOU ${ }^{4}$, Antonis ZORPAS ${ }^{4}$, Ioanna KAKABOUKI ${ }^{2}$ \\ ${ }^{1}$ Agricultural University of Athens, Laboratory of Crop Production, Iera Odos 75, 11855 \\ Athens, Greece; bilalisdimitrios@yahoo.gr (*corresponding author) \\ ${ }^{2}$ University of West Greece, Department of Business Administration of Food and Agricultural \\ Enterprises, Seferi 2, 30100,Agrinio, Greece; i.kakabouki@yahoo.gr \\ ${ }^{3}$ University of Thessaly, Department of Agriculture Crop Production and Rural Environment, \\ Fytokou Str, 38446, Magnesia, Greece; anekark80@yahoo.gr \\ ${ }^{4}$ Open University of Cyprus, P.O. Box 24801, 1304 Nicosia, Cyprus; sissyefthimiadou@yahoo.gr
}

\begin{abstract}
Maize (Zea mays L.) and tomato (Solanum lycopersicum L.) are two important crops in Mediterranean countries. The objectives of this study were to evaluate the differences and similarities in energy flow between conventional and organic tomato and maize crops. Our results indicated that the total energy input in the conventional system was higher than in organic system and for individual crops was 25.90 and $29.34 \%$ higher for tomato and maize, respectively, than the organic system. Of the inputs for the different operations, fertilizers consumed the bulk of the energy for all crops. In maize crop, human labour had little impact on total energy use both in organic and conventional system. In addition, seed inputs in maize production had corresponded to $11.44 \%$ of the total energy requirement. Concerning the pesticides inputs, there were significant differences between organic and conventional systems. In both crops, the pesticides energy input was higher in conventional production compared to organic system. Moreover, irrigation inputs were $13-23 \%$ of the total energy use in the organic system and $12-20 \%$ in the conventional system. In both crops, the energy output and energy productivity were also higher in conventional production compared to organic system. Our study shows that the adoption of organic cultural system could reduce energy inputs.
\end{abstract}

Keywords: energy inputs, energy use efficiency, horticulture, field crops, tomato, maize

\section{Introduction}

Organic agriculture is a farming system that is considered by some to have beneficial impacts on the future sustainability of agriculture (Wheeler, 2008). A key issue in the debate on the contribution of organic agriculture to the future of world agriculture is whether organic agriculture can produce sufficient food to feed the world. Comparisons of organic and conventional yields play a central role in this debate (De Ponti et al., 2012).

Conventional agriculture uses herbicides, pesticides, and chemical fertilizers that have the potential to pollute the surrounding land, air and water. Organic agriculture tries to avoid using these and promotes an environmentally friendly approach to agriculture (Adl et al., 2011). Among the benefits of organic agriculture are higher soil organic matter and nitrogen, lower fossil energy inputs, conservation of soil moisture and water resources (especially advantageous under drought conditions), and yields similar to those of conventional systems (Pimentel et al., 2005).
Organic agriculture both utilizes and maintains ecosystem services. Ecosystem services, such as biological control, pollination, soil formation, nutrient cycling in agriculture are vital for the sustainable supply of food. It is therefore more sustainable than is conventional agriculture which degrades some ecosystem services (Sandhu et al., 2010). Organic agriculture, on the other hand, through its ecological approach, promotes biodiversity and maintains the integrity of the ecosystem. Research into organic agricultural practices has shown that organic systems can support biodiversity conservation through increasing the number and variety of wild species found on farms and supporting high levels of agrobiodiversity (Grandi, 2008).

Moreover, looking at the future of organic farming, there is clearly a need for more research and investment directed to exploring potential of organic farming for reducing the environmental impact of agricultural practices (Gomiero et al., 2011). The current situation of worldwide concern over the emission of greenhouse gases and its effect on the climate demands an evaluation, from the per- 
spective of energy efficiency and more specifically of nonrenewable energy sources, of tendencies for change in the management of agricultural systems which have arisen in recent years (Guzmán and Alonso, 2008).

Today's agricultural production relies heavily on the consumption of non-renewable fossil fuels. Consumption of fossil energy results in direct negative environmental effects through release of $\mathrm{CO}_{2}$ and other combustion gases (Gündoğmuş, 2006). Organic farming holds an especially favourable position, in reducing energy inputs and greenhouse gas-emissions in an efficient way (Michos et al., 2012). The objectives of this study were to evaluate the differences and similarities in energy flow among conventional and organic farming systems. An energy analysis in conventional and organic crops is useful in evaluating present situation and deciding best management strategies.

\section{Materials and methods}

The study was conducted in Western Greece, during 2010-2011. The energy analysis presented in this study compared the energy performance of two cropping systems (organic and conventional) managed according to different input intensities. Data were collected through personal interviews with farmers. Sixty farmers, who owned maize, tomato and olive farms, were randomly selected to participate in this study [( 30 conventional and 30 organic) and two crops: maize (Zea mays L.) and tomato (Solanum lycopersicum L.)]. The information for man-hours, pesticides and fertilisers inputs, machinery and energy consumption were collected. The whole procedure of the research can be summarized to the following steps (Konstantas et al., 2011):

- Selection of the most suitable questions and creation the structure of the questionnaires;

- Selection of the farmers that will participate in the completion of the questionnaires;

- Establishing the interviews and completion of questionnaires;

- Recording of the answers and transfer in electronic form;

- Analysis of the questionnaire answers with the use of a statistical software (SIGMAPLOT 12).

The energy equivalents of the inputs used in the maize and tomato production are illustrated in Tab. 1. The data of the energy use have been taken from a number of sources. After analyzing the results from the questionnaires, valuable information about energy input in organic and conventional agriculture in Greece, from the perspective of the directly involved farmers, were unveiled. Based on the energy equivalents of the inputs and output, the energy ratio (energy use efficiency) and energy productivity, were calculated (Singh et al., 1997):

$$
\begin{aligned}
& \text { Energy use efficiency }=\frac{\text { Energy output }\left(K J \mathrm{Ka}^{-1}\right)}{\text { Energy input }\left(K J \mathrm{~K}^{-1}\right)} \\
& \text { Energy productivity }=\frac{\text { Yield }\left(\mathrm{kgha}^{-1}\right)}{\text { Energy input }\left(K J \mathrm{Ka}^{-1}\right)}
\end{aligned}
$$

\begin{tabular}{|c|c|c|}
\hline Inputs & $\begin{array}{c}\text { Energy Equivalent } \\
(\mathrm{MJ} / \text { unit })\end{array}$ & References \\
\hline Human labour (eg. harvest, pruning, weed control) [h] & 1.96 & Heidari et al. (2012) \\
\hline \multicolumn{3}{|l|}{ Chemical fertilizers $(\mathrm{kg})$} \\
\hline Nitrogen & 60.6 & Gündoğmuş (2006) \\
\hline Phosphorus & 11.1 & Gündoğmuş (2006) \\
\hline Potassium & 6.7 & Gündoğmuş (2006) \\
\hline \multicolumn{3}{|l|}{ Organic fertilizers } \\
\hline Farmyard manure (kg) & 0.3 & Heidari et al. (2012) \\
\hline Commercial compost $(\mathrm{kg})$ & 10.5 & Guzmán et al. (2008) \\
\hline Green manure; vetch ( $\mathrm{kg}$ seed $)$ & 15.9 & Guzmán et al. (2008) \\
\hline \multirow{3}{*}{$\begin{array}{c}\text { Corn } \\
\text { Tomato } \\
\end{array}$} & 104 & Patzek (2004) \\
\hline & 1 & Singh (2002) \\
\hline & & \\
\hline Herbicides (kg) & $\begin{array}{l}263 \text { (mean value of } \\
\text { different herbicides) }\end{array}$ & Clements et al. (1995) \\
\hline Fungicides (kg) & 92 & Gündoğmuş (2006) \\
\hline Coppers and sulfurs & 176 & Guzmán and Alonso (2008) \\
\hline Insecticides (kg) & 199 & Gündoğmuş (2006) \\
\hline Bacillus thuringiensis & 77.2 & Guzmán and Alonso (2008) \\
\hline Irrigation $\left(\mathrm{m}^{3}\right)$ & 0.63 & Heidari et al. (2012) \\
\hline Machinery (e.g mouldboard plow, rotary hoe, field spraying, transportation) (h) & 62.7 & Gündoğmuş (2006) \\
\hline Output-tomato & 0.8 & Ozkan et al. (2011) \\
\hline Output-maize & 14.7 & Sartoni et al. (2005) \\
\hline
\end{tabular}

Tab. 1. Energy equivalent of inputs in agricultural production 
192

\section{Results and discussion}

Knowledge about fossil energy use in agricultural systems is needed, because it can improve the understanding of how to reduce the unsustainable use of limited energy resources and the following greenhouse gas emissions (Dalgaard et al., 2011). Total energy input consisted of human labour, fertilizers, pesticides, seeds, machinery and irrigation. The energy equivalents were used to determine energy inputs and outputs. The energy inputs for maize and tomato production vary with the method of production (Fig. 1 and 2). The total energy input in the conventional system was higher than in organic system and for individual crops was 25.90 and $29.34 \%$ higher for tomato and maize, respectively, than the organic system. More- over, Dalgaard et al. (2011) compared the energy use for eight conventional and organic crops. The energy use was generally lower in the organic than in the conventional system, but yields were also lower.

Human labour, fertilizers, irrigation and machinery equipment in organic $(13.45,54.97,13.42$ and $15.7 \%$ respectively) and in conventional tomato crops (8.52, $62.51,12.15$ and $11,95 \%$ respectively) were the highest energy inputs. In maize crop fertilizers, irrigation, seeds and machinery equipment in organic $(51.35,23.70,12.62$ and $8.99 \%$ respectively) and in conventional production system $(56.69,20.25,10.25$ and $7.13 \%$ respectively) were the highest energy inputs. Of the inputs for the different operations, fertilizers consumed the bulk of the energy for all crops. In maize crop, human labour had little impact on

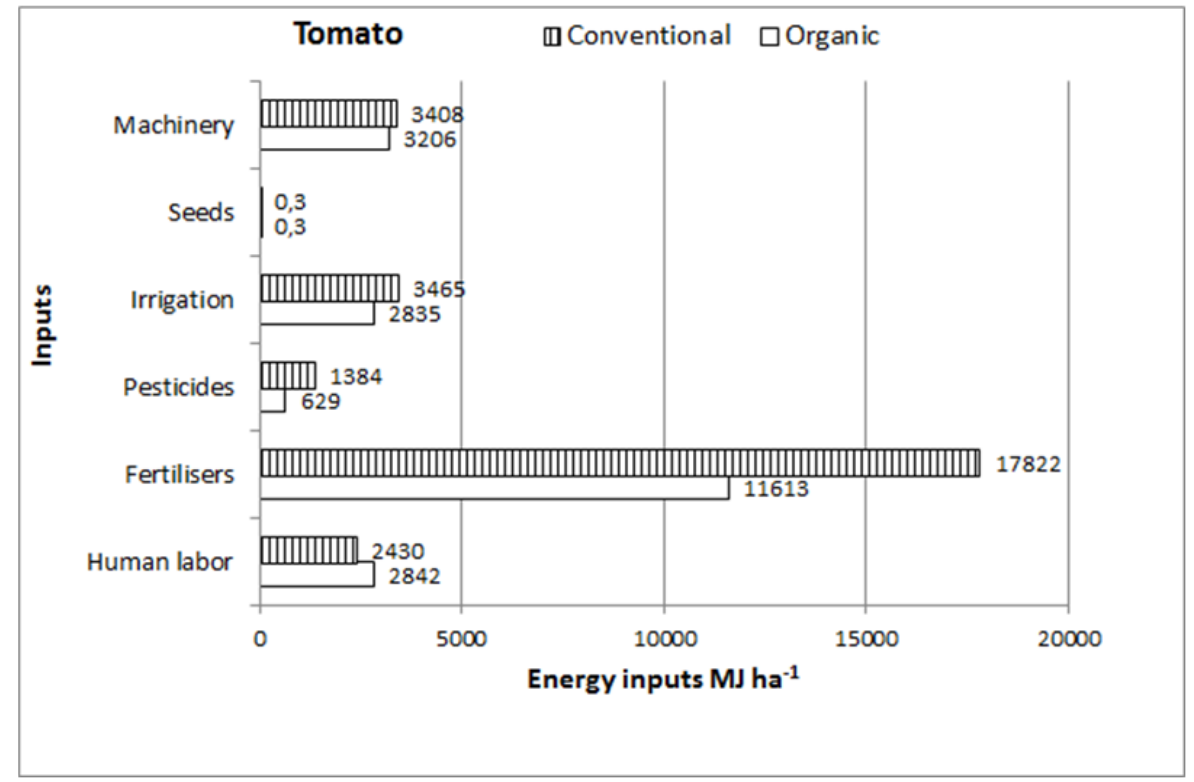

Fig 1. Energy inputs $\left(\mathrm{MJ} \mathrm{ha}^{-1}\right)$ in organic and conventional tomato crop production

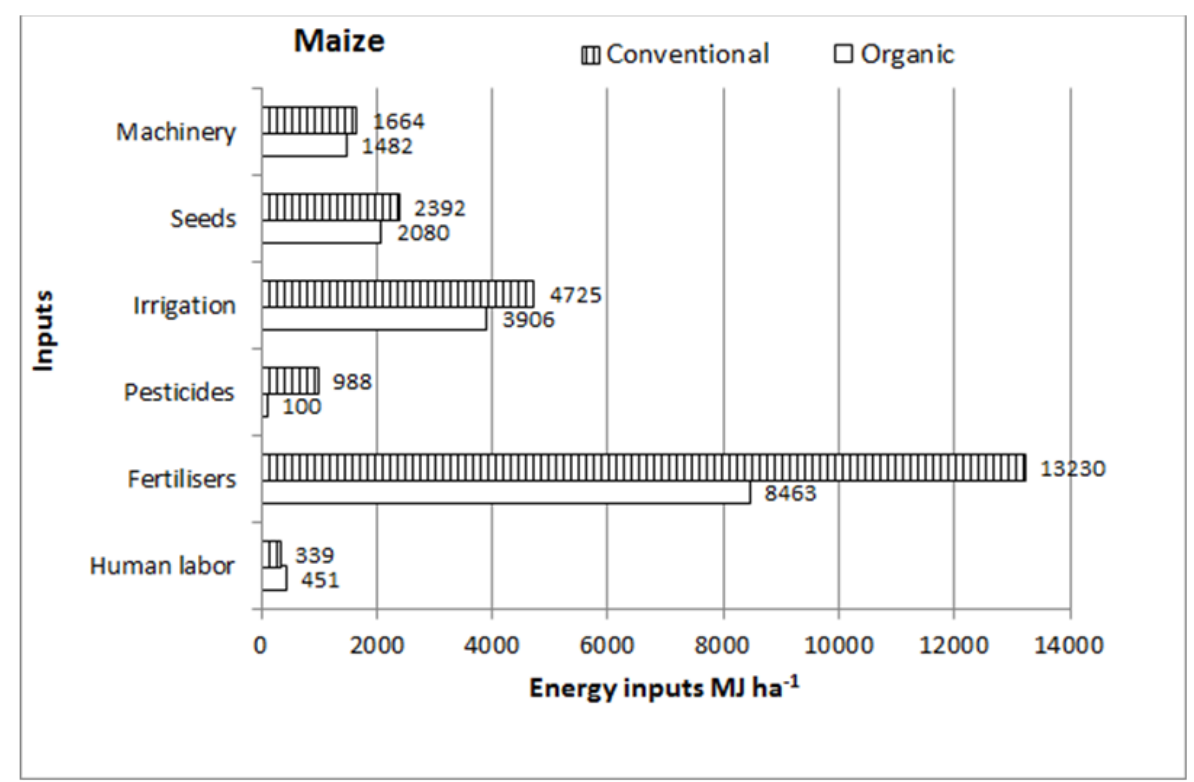

Fig 2. Energy inputs $\left(\mathrm{MJ} \mathrm{ha}^{-1}\right)$ in organic and conventional maize crop production 
total energy use both in organic and conventional system. Sartoni et al. (2005) also reported that human labour had little impact on energy requirement. Our results indicated that seed inputs had corresponded to $11.44 \%$ of the total energy requirement. The production of hybrid maize seeds is very intensive. About seven times more energy is required to produce hybrid seeds compared with the energy in the same amounts of maize grain (Patzek, 2004).

Concerning the pesticides inputs, there were significant differences between organic and conventional systems (Fig. 3). In both crops, the pesticides energy input (e.g. herbicides) was higher in conventional production compared to organic system. Clements et al. (1995) also reported that energy was conserved in alternative weed management systems by elimination or reduction strategies for tillage and/or herbicide use. The most alternative methods of weed control (e.g. reduced herbicide and tillage) are more energy efficient than conventional weed control practices (e.g. broadcast application of herbicides at recommended rates) (Clements et al., 1995). Furthermore, in the agricultural systems with reduced inputs the costs and the environmental risk due to herbicide use decrease (Gerowitt et al., 2000).

Irrigation inputs were 13-23\% of the total energy use in the organic system and $12-20 \%$ in the conventional system. Irrigation systems are generally characterized by a greater discharge than that which usually flows in drinking water supply systems. Moreover, they are supplied in limited periods of the year (irrigation periods) and sometimes a pump station with a high level of energy consumption could be needed (De Marinis et al., 2006). As a result of global climate change, precipitation may decrease in some regions and water stored in lakes and reservoirs may suffer increased losses due to evaporation, reducing the water available for irrigation. So, urgent need for the most efficient use of existing water resources has enforced nations to give top priority to water saving technologies (Sener, 2011). The energy analysis can indicate ways to decrease energy inputs (fertilizers, plant protection products, irrigation etc.) without losses in production and economic benefits of farmers (Kavargiris et al., 2009). The subsurface irrigation methods seems very promising and should seriously be considered in future studies of farming systems with low inputs.

Concerning the energy output, there were significant differences between organic and conventional systems (Tab. 2). In both crops, the energy output was higher in conventional production compared to conventional system. In maize crop, the energy use efficiency was also higher in the organic system than in conventional system. In addition, the energy use efficiency was lower in the organic tomato crop than in conventional crop. Dalgaard et al. (2011) and Sartoni et al. (2004) also reported that the conventional crop production had the highest energy pro-

Tab. 2. Yield $\left(\mathrm{kg} \mathrm{ha}^{-1}\right)$, energy output and input $\left(\mathrm{KJ} \mathrm{ha}^{-1}\right)$, energy use efficiency (EUE) and energy productivity (EP) in organic and conventional cropping systems

\begin{tabular}{ccccc}
\hline & \multicolumn{2}{c}{ Tomato } & \multicolumn{2}{c}{ Maize } \\
\cline { 2 - 5 } & organic & conventional & organic & conventional \\
\hline Yield & 40300 & 63500 & 11500 & 13700 \\
Energy input & 21125 & 28510 & 16482 & 23338 \\
Energy output & 32240 & 50800 & 169050 & 201390 \\
EUE & 1.53 & 1.78 & 10.26 & 8.63 \\
EP & 0.52 & 0.45 & 0.70 & 0.59 \\
\hline
\end{tabular}

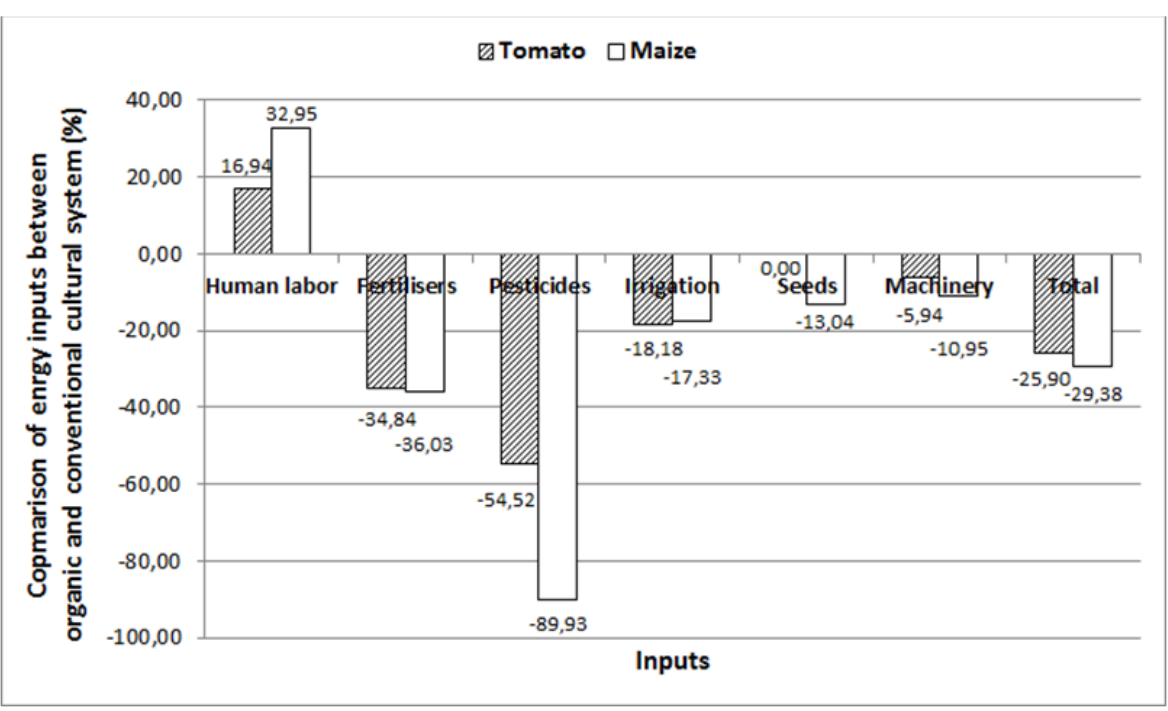

Fig. 3. Energy use in organic maize and tomato crops relative to conventional systems 
194

duction, whereas organic crop production had the highest energy efficiency. Moreover, the energy productivity (Tab. 2 ) was higher in the organic system than in conventional system.

\section{Conclusions}

Our results indicated that the energy inputs for maize and tomato production vary with the method of production. In tomato and maize crops, fertilizers, irrigation and machinery equipment were the highest energy inputs. In maize crop, human labour had little impact on total energy use both in organic and conventional system. Concerning the pesticides inputs, there were significant differences between organic and conventional systems. In both crops, the pesticides energy input was higher in conventional production compared to organic system. Moreover, the energy output was higher in conventional cultural system compared to organic system. Final, the energy productivity was higher in the organic system than in conventional system.

\section{References}

Adl S, Iron D, Kolokolnikov T (2011). A threshold area ratio of organic to conventional agriculture causes recurrent pathogen outbreaks in organic agriculture. Science of the Total Environment 409:2192-2197.

Clements DR, Weise SF, Brown R, Stonehouse DP, Hume DJ, Swanton CJ (1995). Energy analysis of tillage and herbicide inputs in alternative weed management systems. Agriculture, Ecosystems \& Environment 52:119-128.

Dalgaard T, Halberg N, Porter JR (2001). A model for fossil energy use in Danish agriculture used to compare organic and conventional farming. Agriculture, Ecosystems and Environment 87:51-65.

De Marinis G, Russo A, Del Greco A (2006). Energy revenue in irrigation systems: A case study. WIT Transactions on Ecology and the Environment 96:313-320.

De Ponti T, Rijk B, van Ittersum MK (2012). The crop yield gap between organic and conventional agriculture. Agricultural Systems 108:1-9.

Gerowitt B, De Mol F, Moerschner J, Steinman HH (2000). Characterisation of weed management in different farming systems compared to the costs, the energy input, the environmental risk due to herbicides and the field vegetation. Zeitschrift fur Pflanzenkrankheiten und Pflanzenschutz 107 (SPEC. ISS. 17):725-734.

Gomiero T, Pimentel, D, Paoletti MG (2011). Environmental impact of different agricultural management practices: conventional vs. organic agriculture. Critical Reviews in Plant Sciences 30:95-124.

Grandi C (2008). Organic agriculture enhances agrobiodiversity. Biodiversity 9: 33-35.

Gündoğmuş E (2006). Energy use on organic farming: A com- parative analysis on organic versus conventional apricot production on small holdings in Turkey. Energy Conversion and Management 47:3351-3359.

Guzmán GI, Alonso AM (2008). A comparison of energy use in conventional and organic olive oil production in Spain. Agricultural Systems 98:167-176.

Heidari MD, Omid M, Mohammadi A (2012). Measuring productive efficiency of horticultural greenhouses in Iran: a data envelopment analysis approach. Expert Systems with Applications 39:1040-1045.

Kavargiris SE, Mamolos AP, Tsatsarelis CA, Nikolaidou AE, Kalburtjia KL (2009). Energy resources' utilization in organic and conventional vineyards: Energy flow, greenhouse gas emissions and biofuel production. Biomass and Bioenergy 33:1239-1250.

Konstantas A, Bilalis D, Mpeopoulos N, Karkanis A, Patsiali S (2011). A survey concerning organic, integrated and conventional agriculture in Greece. Bulletin UASVM Horticulture 68(2):120-126.

Michos MC, Mamolos AP, Menexes GC, Tsatsarelis CA, Tsirakoglou VM, Kalburtji KL (2012). Energy inputs, outputs and greenhouse gas emissions in organic, integrated and conventional peach orchards. Ecological Indicators 13:2228.

Ozkan B, Ceylan RF, Kizilay H (2011). Energy inputs and crop yield relationships in greenhouse winter crop tomato production. Renewable Energy 36:3217-3221.

Patzek TW (2004). Thermodynamics of the Corn-Ethanol Biofuel Cycle. Critical Reviews in Plant Sciences 23:519-567.

Pimentel D, Hepperly P, Hanson J, Douds D, Seidel R (2005). Environmental, energetic, and economic comparisons of organic and conventional farming systems. BioScience 55:573582.

Sandhu HS, Wratten SD, Cullen R (2010). Organic agriculture and ecosystem services. Environmental Science \& Policy 13:1-7.

Sartoni L, Basso B, Bertocco M, Oliviero G (2005). Energy use and economic evaluation of a three year crop rotation for conservation and organic farming in NE Italy. Biosystems Engineering 91:245-256.

Sener S (2011). Global climate change and its effects on irrigation in Mediterranean region-Water and energy saving irrigation systems and some relevant research results. Acta Horticulturae 92:107-112.

Singh JM (2002). On farm energy use pattern in different cropping systems in Haryana, India. International Institute of Management University of Flensburg, Sustainable Energy Systems and Management. Master of Science, Germany.

Singh MK, Pal SK, Thakur R, Verma UN (1997). Energy inputoutput relationship of cropping systems. Indian Journal of Agricultural Science 67(6):262-266.

Wheeler SA (2008). What influences agricultural professionals' views towards organic agriculture? Ecological Economics 65:145-154. 